\title{
Shear and Longitudinal Modulus of Elasticity in Structural Profiled Round Timber Beams
}

\author{
André L. Chris toforo ${ }^{1, *}$, Felipe H. Icimoto ${ }^{2}$, Caio Victor Fernandes ${ }^{3}$, \\ Juliano Fiorelli ${ }^{4}$, João Negrão ${ }^{5}$, Francisco A. Rocco Lahr $^{6}$ \\ ${ }^{1}$ Department of Mechanical Engineering, Federal University of São João del-Rei, São João del-Rei, 36307-352, Brazil
${ }^{2}$ Department of Science and En gineering Materials, En gineering School of São Carlos (EESC/U SP), São Carlos, 13566-590, Brazil
${ }^{3}$ Department of Forestry Engineering, Paulista State University (UNESP), Itap eva, 18409-010, Brazil
${ }^{4}$ Department of Biosystems Engineering, São Paulo State University (FZEA/USP), Pirassununga, 13635-900, Brazil
${ }_{5}^{5}$ Department of Structural Engineering, Coimbra University (UC), Coimbra, 74691070, Portugal
${ }^{6}$ Department of Structural Engineering, School of Engineering of São Carlos (EESC/USP), São Carlos, 13566-590, Brazil
}

\begin{abstract}
This research aimed to present, with the aid of the three-points static bending, conducted nondestructively, analytical methodology to determine the longitudinal $(E)$ and the shear modulus $(G)$ of elasticity in round timber beams. The wood used was Eucalyptus clones. Were used three different values to the form factor coeffic ient of the circular cross section, allowing evaluating the differences between the shear stiffness values obtained. The results of the analysis of variance indicated no statistical equivalence between the shear modulus of elasticity, revealing be significant the influence of the form factors used to determine the shear modulus of elasticity. The coefficient $(\lambda)$ of the relationship between the modulus of elasticity $(E=\lambda \cdot G)$ obtained from the least squares method were equal to 118 , revealing 5.9 higher than the relationship $(E=20 \cdot G)$ p resented in the Brazilian standard ABNT NBR 7190:1997. It is emphasized that these results may be different for the same or different wood species, justifying the use of this methodology in each research developed.
\end{abstract}

Keywords Stiffness, Profiled Round Timber, Beams Theory

\section{Introduction}

The shear modulus of elasticity of timber pieces, as well as other materials, presents as a fundamental structural variable especially in designs involving short beams and parts subject to the action of the torsion[1-3].

For the design of various structures in wood, such as silos, roofs, buildings, bridges, among others, engineers, architects and designers make use of normative documents, such as the Brazilian standard ABNT NBR 7190:1997 (Design of Structures Wood), which does not address the anisotropy of wood, with an empirical relationship for obtaining the shear modulus of elasticity $(G)$ known longitudinal modulus of elasticity $(E)$ expressed as: $G=E / 20$, which motivates development of new research on this topic, and highlight the work done by Rocco Lahr[4], Burdzik Nkwera[5], Zangiác omo Rocco Lahr[6] and Christoforo et al.[7].

Rocco Lahr[4] study, among others, the influence of the dimensions of the test pieces of lumber for which the effect of shear forces become negligible in the calculation of displacements, reaching the ratio $L / h \geq 21$, where $L$ is the

* Corresponding author:

alchristo foro@y ahoo.com.br (André L. Christoforo)

Published online at http://journal.sapub.org/ijme

Copyright (C) 2013 Scientific \& Academic Publishing. All Rights Reserved useful length and $h$ is the height of the cross section of the specimen.

Burdzik and Nkwera[5] evaluated the shear and the longitudinal modulus of elasticity in Eucalyptus grandis wooden beams by the transverse vibration wave. The results demonstrate that the proposed method is employable for determining the modulus of elasticity, showing consistency in results when compared with the properties of wood coming from normative document.

Zangiácomo and Rocco Lahr[6] studied the relationship between the length and diameter (D) in round timber beams for which the effect of shear forces becomes negligible in the calculation of displacements, arriving at 24 and 15 relations for the Pinus elliottii and Pinus caribaea wood species, respectively.

Christoforo et al.[7] presented an analytical methodology for the calculation of the shear and longitudinal modulus of elasticity in pieces of lumber, using the three-points static bending, adapted from the Brazilian standard ABNT NBR $7190[8]$, based on the methodology presented by Rocco Lahr[4]. The wood used in the tests were Pinus elliottii and Corymbia citriodora. Equations for the calculation of the elastic moduli were developed according to the method of virtual forces, and the shape of the shear coefficient for rectangular cross section was adopted as 1.20. Results of the coefficients $(\alpha)$ between the modules of elasticity $(E=\alpha \cdot G)$ 
for the Pinus elliottii and Corymbia citriodora wood species were respectively equal to 18.70 and 21.20 , and very close to the coefficient (20) established by the Brazilian standard ABNT NBR 7190[8].

In order to contribute to better understanding of the properties of shear stiffness, this research, based on work carried out by Christoforo et al.[7], aimed to present, with the aid of the three-points static bending and the Timoshenko beams theory, an analytical methodology for obtaining the shear and longitudinal modulus of elasticity in profiled round timber beams with structural dimensions, investigating the influence of the form factor in the calculation of the shear modulus of elasticity.

\section{Material and Methods}

The experimental methodology developed to calculate the modulus of elasticity $E$ and $G$ in structural round timber was based on research developed by Rocco Lahr[4], as also done in the work of Christoforo et al.[7]. The moduli of elasticity were obtained in the condition of geometric linearity, the largest displacements being limited to the experiments L/200 reason, as defined by the small displacements of Brazilian standard ABNT NBR 7190[8].

The Virtual Force Method (VSM) was employed on the structural model of the three-point static bending (Figure 1) in order to obtain the expression for the calculation of the displacement $(\delta)$ at the midpoint of the element, considering the bending moment and shear efforts.

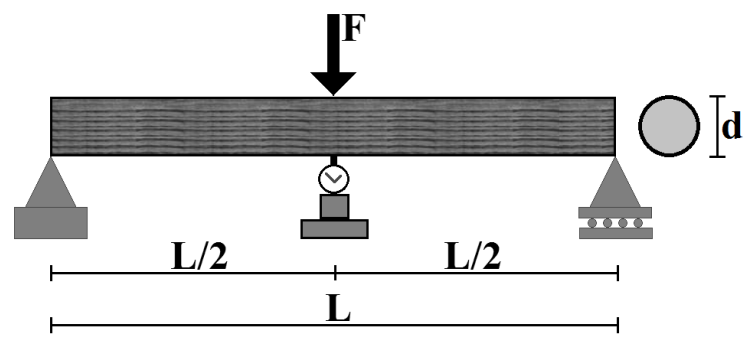

Figure 1. Three-point static bending model

Generically, considering only bending and shearing efforts, displacement at one point of interest is obtained by Equation 1 (MFV), wherein:

$$
1 \cdot \delta=\sum_{i=1}^{n}\left(\int_{\Omega_{i}} \frac{M(x) \cdot m(x)}{E \cdot I} d x+\int_{\Omega_{i}} \frac{f_{S} \cdot Q(x) \cdot q(x)}{G \cdot A} d x\right)
$$

$\delta$ - linear displacement or rotation to be calculated by the use of force or virtual mo ment virtual with module 1 ;

$M(x)$-variation of the bending moment for a section of the structure according to the actual load history;

$m(x)$ - variation of the bending mo ment for a section of the structure according to the employment of a unit force or mo ment applied at one point of interest;

$Q(x)$ - variation of shear for a slice of the structure according to the actual load history;

$q(x)$ - variation of shear for a slice of the structure according to the employment of a unit force or moment applied at one point of interest;

$f_{s}$ - form factor of the cross section (depending on the geometry of the cross sections);

$\Omega$ - integration domain;

$E$ - longitudinal modulus of e lasticity or Young's modulus;

$I$ - moment of inertia of the cross section;

$G$ - shear modulus of elasticity;

$A$ - cross-sectional area;

$L$ - length of the beam.

Using Equation 1 adapted for the structural model of the three-point bending (Figure 1), the displacement at the midpoint is expressed by Equation 2.

$$
\delta=\frac{F \cdot L^{3}}{48 \cdot E \cdot I}+\frac{F \cdot L \cdot f_{s}}{4 \cdot A \cdot G}
$$

According to the present methodology, for calculating the modulus of elasticity are necessary the execution of two successive experimental tests on the same piece, with diameter $d$. The first (Figure 2a), assuming the length of the part $L_{1}$, with $L_{1} / d \geq 21$ [4], it is determined whether the value of the force $F_{1}$ responsible for causing a displacement equal to $\delta_{1}=L 1 / 200$. In the second bending test the supports are approximate (Figure 2b), giving a new useful length $\left(L_{2}\right)$, and must respect the inequality $L_{2} / d \geq 5 / 4$ [9], ensuring that the sections remain plane after deformed, obtaining a value of force $\left(F_{2}\right)$ responsible for causing a displacement magnitude $\delta_{2}=L_{2} / 200$.

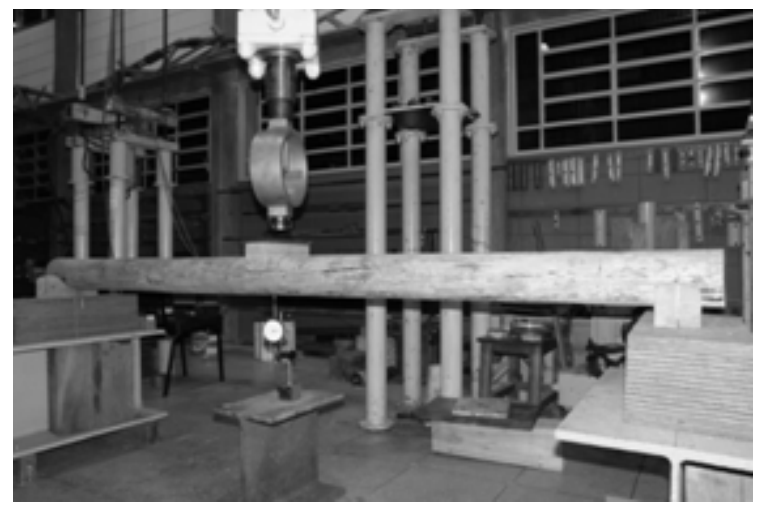

(a)

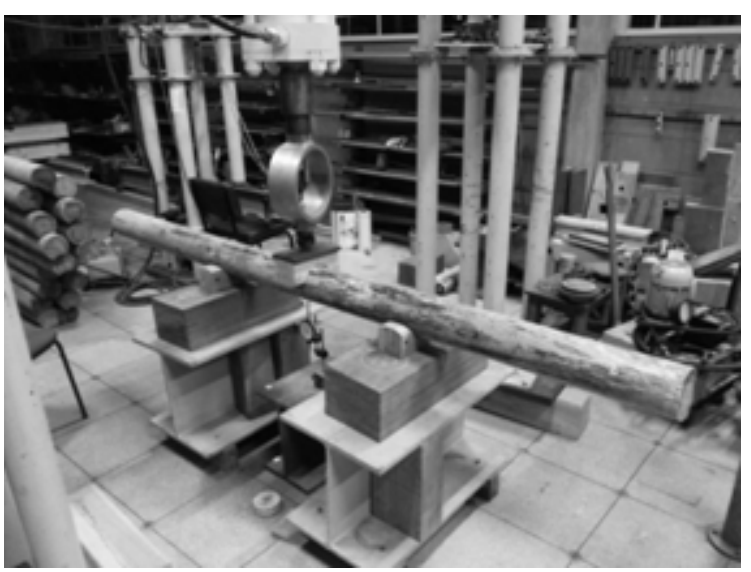

(b)

Figure 2. Bending test in the profile round timber parts: first (a) and the second test (b) 
The use of the forces $F_{1}$ and $F_{2}, L_{1}$ and $L_{2}$ measures and displacement $\delta_{1}$ and $\delta_{2}$ obtained in the tests in Equation 2 leads to a system with two equations in two variables, whose solution provides the shear and the longitudinal modulus of elasticity, respectively expressed by Equations 3 and 4 .

$$
\begin{aligned}
& E=\frac{4 \cdot F_{1} \cdot F_{2} \cdot L_{1} \cdot L_{2} \cdot\left(L_{1}{ }^{2}-L_{2}{ }^{2}\right)}{3 \cdot \pi \cdot d^{4} \cdot\left(F_{2} \cdot L_{2} \cdot \delta_{1}-F_{1} \cdot L_{1} \cdot \delta_{2}\right)} \\
& G=\frac{f_{s} \cdot F_{1} \cdot F_{2} \cdot L_{1} \cdot L_{2} \cdot\left(L_{1}{ }^{2}-L_{2}{ }^{2}\right)}{\pi \cdot d^{2} \cdot\left(F_{1} \cdot L_{1}{ }^{3} \cdot \delta_{2}-F_{2} \cdot L_{2}{ }^{3} \cdot \delta_{1}\right)}
\end{aligned}
$$

Equations 3 and 4 used to obtain the elasticity modulus not take into consideration the own weight of the structural elements. However, Christoforo et al.[7] proved negligible influence of self-weight in the calculation of displacements, validating the methodology presented here.

The proposed methodology was used in wooden beams of Eucalyptus genus. Eighteen structural profiled pieces were used, with medium size $13 \mathrm{~cm}$ in diameter and $234 \mathrm{~cm}$ in length.

The usable length used in bending tests were $L_{1}=234 \mathrm{~cm}$ and $L_{2}=91 \mathrm{~cm}$, being obtained in each specimen the forces values responsible for causing the displacement of $1.17 \mathrm{~cm}$ $\left(L_{1} / 200\right)$ and $0.46 \mathrm{~cm}\left(L_{2} / 200\right)$.

The form factor $\left(f_{s}\right)$ present in the shear modulus of elasticity is a constant that depends on the geometry of the cross section of the piece. In the literature, for the circular cross-section, some authors have different values of form factors. In order to evaluate the influence of emp loyment of form factor for circular sections in the shear modulus of elasticity, these were varied, assuming the values: 0.750 , 0.847 and 0.900 , respectively obtained from the works of Timoshenko[10], Mindlin and Deresiewicz[11] and Roark[12].

To check the influence of the form factor for calculating the elastic modulus, analysis of variance (ANOVA) was used, evaluated at a significance level $(\alpha)$ of $5 \%$, and the equivalence between averages for the shear modulus of elasticity as null hypothesis $\left(H_{0}\right)$ and the non-equivalence between means as alternative hypothesis $\left(H_{l}\right)$. P-value greater than the significance level of the test involves accepting $H_{0}$, rejecting it otherwise.

For validation of ANOVA were investigated normality in the distribution of the shear modulus of elasticity and homogeneity of variances, with the aid of the Anderson-Darling test and Bartlett and Levene tests, respectively, both at the $5 \%$ level of significance.

For the Anderson Darling test, the null hypothes is was to assume normal distribution, and the non-normality as the alternative hypothesis. P-value greater than $5 \%$ implies accepting $H_{0}$, rejecting it otherwise. The Bartlett and Levene tests were formulated considering the equivalence between the variances as null hypothesis and alternative hypothes is as non-equivalence. P-value greater than the significance level involves accepting $H_{0}$, rejecting it otherwise.

In order to relate the values of the modulus of elasticity $\mathrm{E}$ and $\mathrm{G}$ and compared with the relationship defined by the Brazilian standard ABNT NBR 7190:1997, was used the least squares method[7, 13], exp ressed by Equation $5, \lambda$ is the coefficient to be adjusted at the discretion of the smaller residue $(E=\lambda \cdot G)$.

$$
f(\alpha)=\frac{1}{2} \cdot \sum_{i=1}^{n}\left(E_{i}-\lambda \cdot G_{i}\right)^{2}
$$

\section{Results}

Table 1 shows the results of the two modulus of elasticity, $\bar{x}$ is the sample mean and $C v$ the variation coefficient.

Table 1. Shear and longitudinal modulus of elast icity

\begin{tabular}{ccccc}
\hline & & \multicolumn{3}{c}{$\mathbf{G}$ (MPa) } \\
\hline & $\mathbf{E}(\mathbf{M P a})$ & $f_{s}=0,750$ & $f_{s}=0,847$ & $f_{s}=0,900$ \\
\hline 17139 & 77 & 97 & 125 \\
17162 & 85 & 107 & 137 \\
16224 & 99 & 126 & 161 \\
15091 & 77 & 98 & 125 \\
14525 & 109 & 139 & 178 \\
16865 & 81 & 103 & 131 \\
14328 & 81 & 104 & 132 \\
& 12816 & 83 & 106 & 136 \\
15637 & 105 & 134 & 170 \\
12480 & 107 & 136 & 173 \\
11739 & 137 & 175 & 222 \\
& 17153 & 103 & 131 & 168 \\
12384 & 96 & 122 & 156 \\
& 15555 & 90 & 114 & 146 \\
12888 & 71 & 90 & 115 \\
\hline $\bar{x}(\%)$ & 14786 & 96 & 122 & 156 \\
\hline & 12521 & 93 & 119 & 151 \\
& 14740 & 133 & 168 & 215 \\
& 16907 & 104 & 132 & 168 \\
\hline & & & 19 & 19 \\
\hline
\end{tabular}

Figure 3 illustrates the results of the normality test and homogeneity of variance between means for Eucalyptus wood, respectively. By P-values are both higher than the significance level $(0.05)$, we see that the properties of stiffness shows normal distribution and that the variances for the shear modulus are equivalent, validating the ANOVA model.

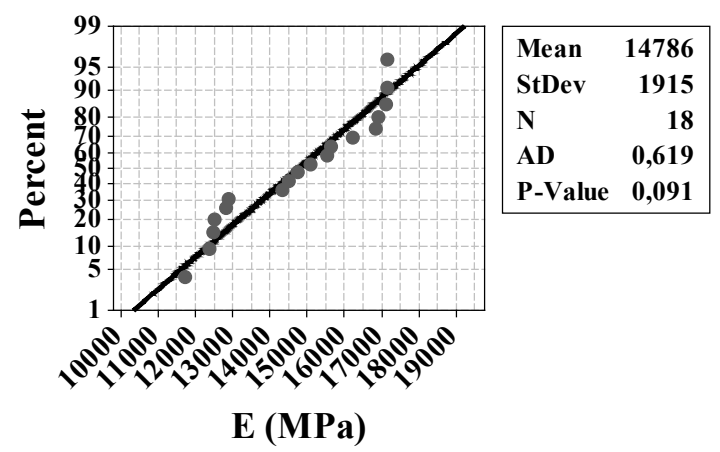

(a) 


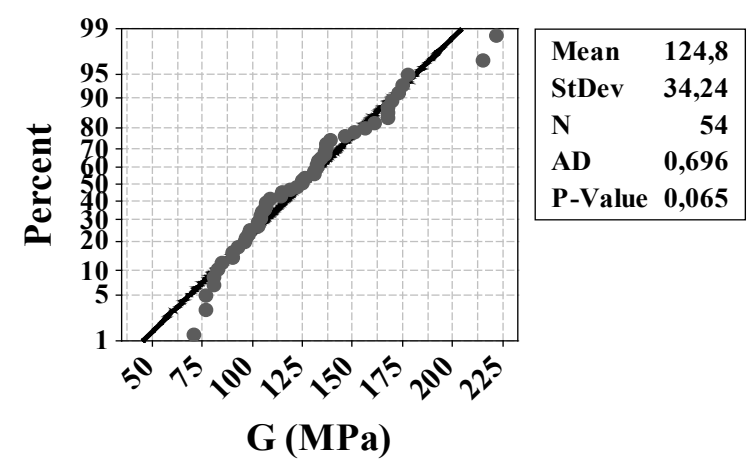

(b)

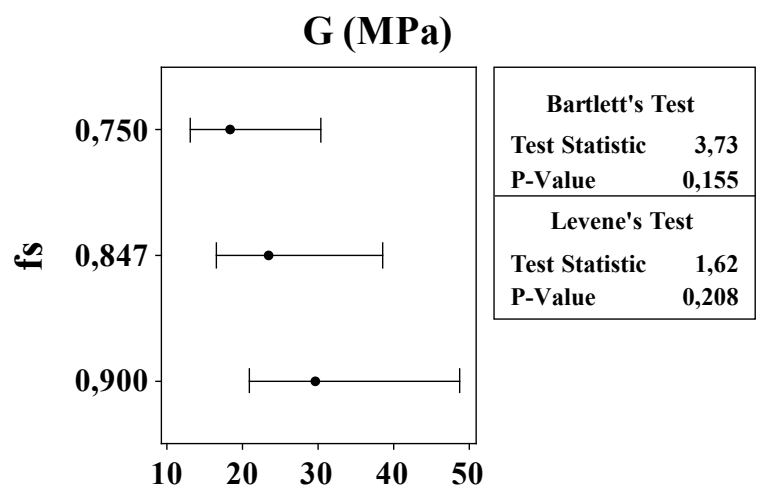

(c)

Figure 3. Results of normality test $(a, b)$ and homogeneity of variances (c)

Table 2 shows the ANOVA results. The P-value was equal to 0.000 , proving to be a significant factor in order to obtain the shear modulus of elastic ity ( $\mathrm{P}$-value $<0.05$ ).

Table 2. ANOVAresults for the shear modulus of elasticity

\begin{tabular}{cccccc}
\hline Source & DF & SS & MS & F & P-value \\
\hline Form Factor & 2 & 32456 & 16228 & 2787 & $\underline{0,000}$ \\
Error & 51 & 29697 & 582 & & \\
Total & 53 & 62153 & & & \\
\hline
\end{tabular}

Table 3 presents the results of the $\lambda$ coefficients obtained by the least squares method of the relationship between the shear and longitudinal modulus of elasticity.

Table 3. $\lambda$ coefficients between the longitudinal and shear modulus of elasticity

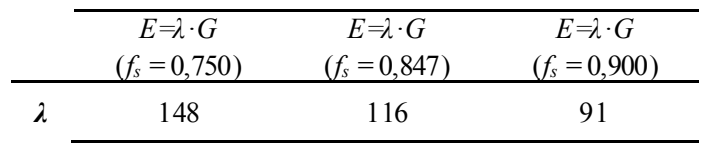

The values of $\lambda$ varied in the range 91-148, whose variation is explained by differences in the values adopted for the form coefficient of cross section $\left(f_{s}\right)$.

The results of the average values of the coefficients $(\lambda)$ between the elastic moduli was equal to 118 , being 5.9 higher than the stipulated ratio between the elastic moduli of the Brazilian standard ABNT NBR 7190[8] $(G=E / 20)$, imply ing in shear modulus of elasticity significantly lower than that presented by this standard.

The ratio between the elastic moduli obtained in this study were on average 6.3 higher than the correlation coefficient between the modules of Pinus elliottii timber (18.70) obtained from the research of Christoforo et al.[7], possibly justified by the sensitivity of this method. For higher values of the shear modulus of elasticity it is necessary to carry out bending tests for ratios $L / d$ lower than the lowest of the relationships here investigated.

\section{Conclusions}

The results of the shear modulus of elasticity for the wood investigated were found to be dependent on the choice of the form coefficients of circular cross-section, providing the shape coefficient of 0.90 the highest values.

The average value of the coefficients of the relationship between the modulus of elasticity of the Eucalyptus wood was significantly higher than the value set by the Brazilian standard, providing values of shear modules less when compared to the shear modulus of this standard.

The sensitivity of the method, the results obtained here should not be extrapolated to woods with the same or different species, thereby justifying the use of this calculation method developed in each study and other relations between length and diameter of the elements different fro $m$ those here evaluated.

\section{REFERENCES}

[1] Calil Jr, C.; Rocco Lahr, F. A.; Dias, A. A. Dimensionamento de elementos estruturais de madeira. 1. ed., Editora Manole Ltda, Barueri - SP, 2003. v. 1. 152p.

[2] Miranda, J. S.; Christoforo, A. L.; Dias, A. M. S. Avaliação do Comportamento de Um Compósito Laminado de Matriz Vitrocerâmico. In: X Simpósio de Mecânica Computacional (SIMMEC). Anais..., Belo Horizonte, MG, 2012.

[3] determinação dos deslocamentos em vigas. In: XII Congresso Nacional de Engenharia Mecânica e Industrial (CONEMI) e Congresso de Engenharias da Universidade Federal de São João del-Rei (COEN), Anais..., São João del-Rei MG, 2012.

[4] Rocco Lahr, F. A. Sobre a determinação de propriedades de elasticidade da madeira. Tese de Doutorado, 216 p., Engenharia de Estruturas. Escola de Engenharia de São Carlos, Universidade de São Paulo, São Carlos, 1983.

[5] Burdzik. W. M. G.: Nkwera. P. D. Transverse vibration tests for prediction of stiffness and strength properties of full size Eucalyptus grandis. Forest Products Journal, v. 52, n. 6, p. 63-67, 2002.

[6] Zangiácomo. A. L; Rocco Lahr, F. A. Avaliação do efeito do cisalhamento na flexão de elementos roliços da espécie Eucalyptus Citriodora. In: XI Encontro Brasileiro em Madeiras e em Estruturas de Madeira, Anais..., Londrina-PR, 2008. 
[7] Christoforo, A. L.; Filho, S. L. M. R.; Panzera, T. H.; Rocco Lahr, F. A. Metodologia para o cálculo dos módulos de elasticidade lon gitudinal e transversal em vigas de madeira de dimensões estruturais. Ciência Rural, v. 43, n.4, p. 610-615, 2013.

[8] Associação Brasileira de Normas Técnicas ABNT NBR 7190. Projeto de Estruturas de Madeira. Rio de Janeiro, 1997.

[9] Sanches Jr., F.; Venturini, W. S. Damage modeling of reinforced concrete beams. Advances in Engineering Software, v. 38, n. 8-9, p. 538-546, 2006.

[10] Timoshenko, S. P. Strength of materials - Part 1. Second edition, D. Van Nostrand Company, Inc., New York, pp. 170-171, 1940.
[11] Mindlin, R. D.; Deresiewicz, H. Timoshenko's shear coefficient for flexural vibration of beams. Technical Report, $\mathrm{n}^{\mathrm{o}} .10$, ONR Project NR064-388, Department of Civil Engineering, Columbia University. New York, 1953.

[12] Roark, R. J. Formula for stress and strain. Third edition, McGraw-Hill Book Company, Inc, New York, pp. 119-121, 1954.

[13] Christoforo, A. L.; Rocco, F. A. L.; Morales, E. A. M.; Panzera, T. H.; Borges, P. H. Numerical Evaluation of Longitudinal Modulus of Elasticity of Eucalyptus grandis Timber Beams. International Journal of Agriculture and Forestry, v. 2,p. 166-170, 2012. 